\title{
Uma Tabela Periódica dos Elementos e seus Íons para Cientistas da Terra
}

\author{
Raquel Franco de Souza \\ Universidade Federal do Rio Grande do Norte - UFRN, Depto. \\ de Geologia, Lab.de Geoquímica, Natal, RN \\ raquel@geologia.ufrn.br \\ L. Bruce Railsback \\ University of Georgia, Dept. of Geology, Athens, Georgia, USA \\ rlsbk@gly.uga.edu
}

\begin{abstract}
This paper presents, in Portuguese of Brazil, An Earth Scientist's Periodic Table of the Elements and Their Ions, originally published in English. Besides showing the elements in their ground state, the main difference is the inclusion of species in this table in multiple oxidation states that occur naturally, which represents more faithfully the conditions that the geoscientists typically face in their daily life. The new table therefore shows many elements multiple times, in different positions, unlike the conventional table. The trends, patterns and interrelationships in mineralogy, geochemistry of soils and sediments, igneous petrology, aqueous geochemistry, isotopic geochemistry and nutrient chemistry become apparent in this innovative presentation format. Thus it represents an important tool for both beginners to researchers at the higher levels of investigation in geochemistry, mineralogy and other related sciences.
\end{abstract}

KEYWORDS: ionic potential, geochemistry, minerals, weathering, nutrients, seawater

RESUMO Este artigo apresenta, em língua portuguesa do Brasil, a Tabela Periódica dos Elementos e seus Íons para Cientistas da Terra, originalmente publicada em inglês. Além de mostrar os elementos em seu estado elementar, o principal diferencial é a incorporação, nesta tabela, das espécies nos múltiplos estados de oxidação que ocorrem naturalmente, o que representa de forma mais fidedigna as condições com as quais os geocientistas normalmente se deparam em seu dia a dia. A nova tabela, consequentemente, mostra muitos elementos por diversas vezes, em diferentes posições, de maneira diferente da tabela convencional. As tendências, padrões, e inter-relações em mineralogia, geoquímica de solos e sedimentos, petrologia ígnea, geoquímica em meio aquoso, geoquímica isotópica e química dos nutrientes, tornam-se perceptiveis neste inovador formato de apresentação. Constitui-se assim em ferramenta importante tanto para iniciantes quanto para os pesquisadores nos níveis mais avançados de investigação em geoquímica, mineralogia e outras ciências afins.

PALAVRAS-CHAVE: potencial iônico, geoquímica, manto, minerais, intemperismo, nutrientes, água do mar

\section{INTRODUÇÃOO}

A Tabela Periódica dos Elementos, formulada por Chancourtois, Meyer e Mendeleev (Farber 1969, Courtney 1999) é de grande utilidade para explicar e predizer relações em química. No entanto, é de menor utilidade nas ciências da Terra. Por exemplo, a tabela não organiza os elementos litófilos, siderófilos e calcófilos em grupos distintos, e não agrupa os elementos nos compartimentos que ocorrem na natureza (p.ex., elementos concentrados no manto, na água do mar ou no solo). Elementos críticos para os processos biológicos encontram-se, analogamente, não agrupados de maneira proveitosa pela tabela periódica convencional. Nesse sentido, a tabela periódica convencional não oferece um bom suporte para o entendimento da química da Terra e sua vida.

A aplicação da tabela periódica convencional dos elementos, no que se refere às ciências da Terra, tem sido desvantajosa porque a maior parte da matéria na, ou próximo à superfície da Terra não se 
encontra no seu estado elementar. Pelo contrário, a maior parte dos átomos da matéria encontrada pelos cientistas da Terra encontra-se na forma carregada. O Si é um exemplo muito bom: Si é comum como $\mathrm{Si}^{4+}$ para os cientistas da Terra, mas poucos destes cientistas têm conhecimento que existe uma pequena quantidade de silício natural no seu estado elementar (Gaines et al. 1977). A utilidade de qualquer documento que sumarize a química para as ciências da Terra seria enfatizada pela inclusão da matéria com carga adicionalmente ao seu estado elementar.

Com isto em mente, este artigo apresenta uma Tabela Periódica dos Elementos e seus Íns para Cientistas da Terra. Nesta tabela, agrupamentos naturais e tendências na geoquímica, química marinha e química dos nutrientes tornam-se aparentes, permitindo uma síntese mais geral da química das ciências da Terra. O resultado é uma visão integrada da geoquímica aplicável do manto para o solo e para a água do mar. Um conceito fundamental na racionalização destes padrões geoquímicos é a diferença na ligação exibida pelos cátions duros e moles, que favorece $\mathrm{O}^{2-}$ e $\mathrm{S}^{2-}$, respectivamente. $\mathrm{O}$ outro conceito refere-se à proporção na qual a carga dos cátions está suficientemente localizada (i.e., o potencial iônico é suficientemente alto) para o estabelecimento de ligações fortes com o $\mathrm{O}^{2-}$ sem causar repulsão entre os cátions. Assim a ligação e coordenação com oxigênio, o elemento mais abun-

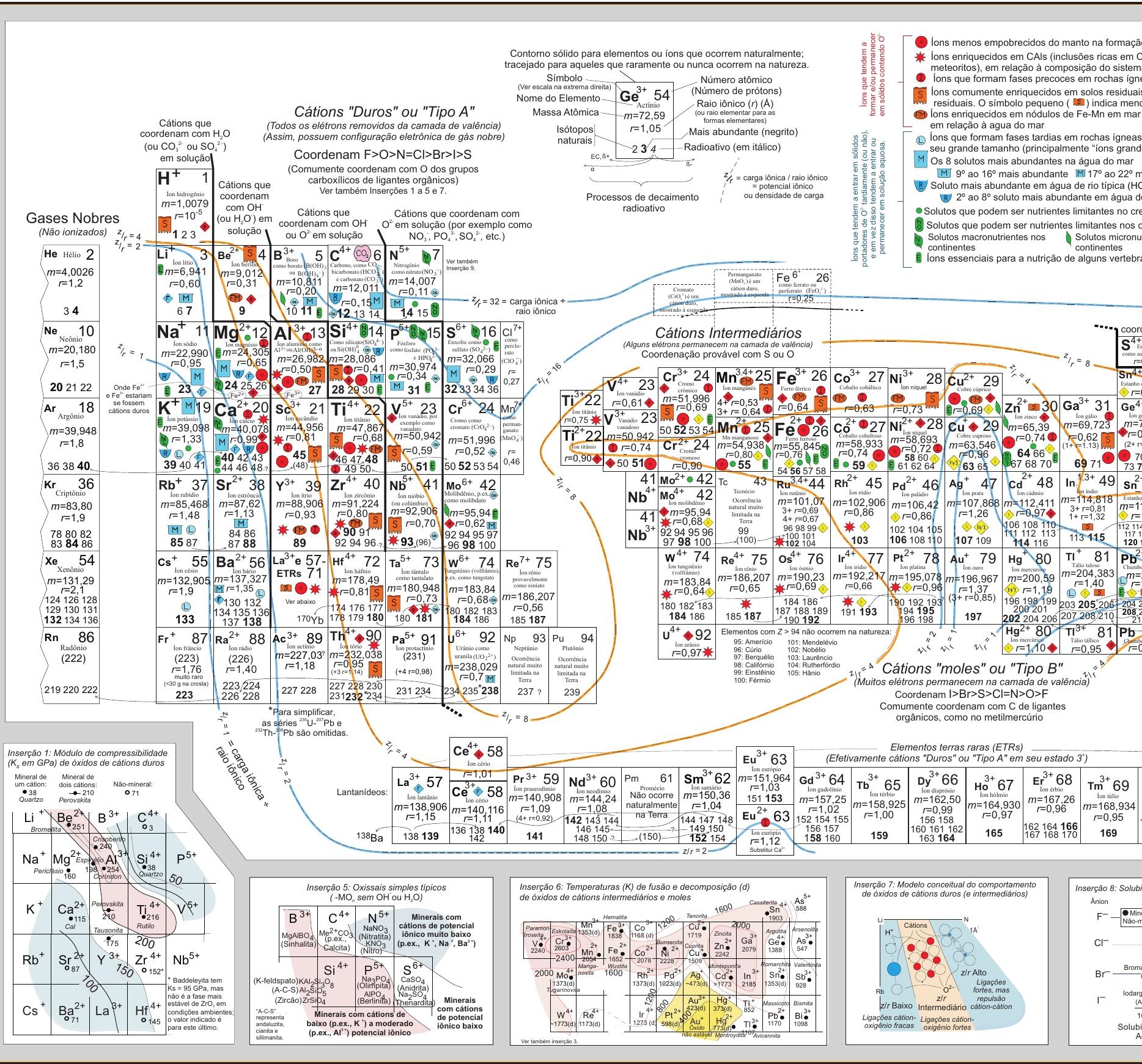


direito da tabela periódica, aparecem à esquerda, na sequência horizontal da esquerda para a direita $\mathrm{Li}^{+}$, $\mathrm{Be}^{2+}, \mathrm{B}^{3+}, \mathrm{C}^{4+}$ e N $^{5+}$. Os elementos $\mathrm{Al}, \mathrm{Si}, \mathrm{P}$ e S, similarmente, aparecem à esquerda na sequência horizontal da esquerda para a direita $\mathrm{Na}^{+}, \mathrm{Mg}^{2+}$, $\mathrm{Al}^{3+}, \mathrm{Si}^{4+}, \mathrm{N}^{5+} \mathrm{e} \mathrm{S}^{5+}$. Um efeito mais surpreendente de organizar a tabela de acordo com a carga é que muitos elementos aparecem várias vezes, porque condições naturais diferentes fazem com que estes elementos assumam cargas diferentes. Assim, muitos elementos (p.ex., P e U) aparecem duas vezes, poucos aparecem três vezes (p.ex., V, Fe, C e N), e uns poucos aparecem quatro vezes (mais particularmente $\mathrm{S}$, como $\mathrm{S}^{2-}, \mathrm{S}^{0}, \mathrm{~S}^{2-}, \mathrm{S}^{4+}$, e $\left.\mathrm{S}^{6+}\right)$.

A Figura 1 (Tabela Periódica dos Elementos e seus Íns para Cientistas da Terra) contém uma legenda no topo que inclui símbolos que mostram ocorrências naturais ou enriquecimento em minerais, águas naturais, solos e sedimentos, rochas ígneas, o manto e a atmosfera, assim como nutrientes críticos. Na porção inferior da figura são incluídas inserções ilustrativas de situações específicas que serão mencionadas no decorrer do texto.

A tabela é interrompida da esquerda para a direita para separar gases nobres, cátions tipo A ou duros (aqueles sem elétrons na camada de valência), cátions intermediários a tipo B ou moles (aqueles com no mínimo alguns elétrons na camada de valência), estado elementar (sem carga), ânions e os gases nobres novamente (Fig. 1). A importância da divisão dos cátions é que os cátions duros ligam-se fortemente a $\mathrm{F}^{-}$e $\mathrm{O}^{2-}$, mas não ligam-se a $\mathrm{S}^{2-}$, enquanto os cátions moles ligam-se fortemente a $\mathrm{S}^{2-}$ e aos haletos grandes $\mathrm{Br}^{-}$e I- (Stumm e Morgan 1996) (Fig. 1, inserção 8). Estes padrões são exemplificados na natureza pela ausência de sulfetos de $\mathrm{Ca}^{2+}$ e dos outros cátions duros, enquanto que existem óxidos e sulfatos destes cátions (Fig. 1). As ocorrências naturais de sulfetos, mas não de óxidos dos íons do grupo da platina fornecem um exemplo oposto (Fig. 1). As diferenças entre cátions duros e moles são adicionalmente ilustradas pelas inserções 3 e 6 , as quais mostram que a temperatura de fusão dos óxidos de potencial iônico intermediário decresce dos cátions duros para os cátions intermediários a moles. A inserção 8 , do mesmo modo, mostra que a solubilidade relativa dos compostos haletos pode ser predita pela divisão dos cátions duros e moles, de forma que a solubilidade dos haletos dos cátions duros aumenta do $\mathrm{F}^{-}$para o $\mathrm{I}^{-}$, enquanto que a solubilidade dos haletos dos cátions moles aumenta do $\mathrm{I}^{-}$para o $\mathrm{F}^{-}$. $\mathrm{Na}$ geoquímica dos processos ígneos, o insucesso do $\mathrm{Cu}^{+}$de ligar-se ao $\mathrm{O}^{2-}$ e substituir o $\mathrm{Na}^{+}$no plagioclásio (Ringwood 1955) fornece um exemplo da diferença de comportamento dos cátions moles e duros, respectivamente. $\mathrm{O}$ insucesso do $\mathrm{Ti}^{+} \mathrm{em}$ substituir o $\mathrm{K}^{+}$, apesar do tamanho e carga similar destes dois cátions, é outro exemplo.

Outra diferença entre a nova tabela e suas predecessoras convencionais é que a nova tabela inclui os actinídeos que ocorrem naturalmente com os cátions duros. $\mathrm{Th}^{4+}$ assim fica abaixo de $\mathrm{Hf}^{4+}$, e $\mathrm{U}^{6+}$ fica abaixo de $\mathrm{W}^{6+}$. As tendências nos símbolos descritos na próxima seção ampliam-se ao longo deste arranjo não convencional, porém útil (Fig. 1).

A tabela também mostra os números atômicos, massas atômicas, isótopos que ocorrem naturalmente, e as etapas de decaimento naturais dos diferentes elementos. Os nomes dos elementos e suas diferentes formas iônicas são mostrados p.ex. "Enxofre como sulfato $\left(\mathrm{SO}_{4}^{2-}\right)$ " para $\mathrm{S}^{6+}$. Os tamanhos dos símbolos químicos são graduados em relação à abundância dos elementos na crosta da Terra; sete dos nove elementos mais abundantes convenientemente encontram-se juntos em uma área ao lado esquerdo da nova tabela. Contornos de mesmo potencial iônico (carga $\div$ raio, i.e., $z / r$ ) realçados em azul e marrom estendem-se transversalmente à tabela e refletem tendências análogas nas ocorrências naturais, conforme será discutido na próxima seção.

\section{OS CONTORNOS DE MESMO POTENCIAL IÔNICO}

O potencial iônico é um parâmetro que caracteriza o quão firmemente encontra-se focada a carga de um íon, ou o quão densa é sua carga.

Potencial iônico $=$ "densidade de carga" = carga do íon / raio do íon $=\mathrm{z} / \mathrm{r}$

$$
\begin{array}{llll}
\text { Para o } \mathrm{Ca}^{2+}: & z=2 & \mathrm{r}=1.0 \AA & \mathrm{z} / \mathrm{r}=2 \\
\text { Para o } \mathrm{N}^{5+}: & \mathrm{z}=5 & \mathrm{r}=0.11 \AA & \mathrm{z} / \mathrm{r}=45
\end{array}
$$

$\mathrm{O} \mathrm{Ca}^{2+}$ tem um potencial iônico baixo, associado com uma carga difusa. Em contraste, com o $\mathrm{N}^{5+}$, a carga mais alta e o raio menor dão um valor de potencial iônico grande, o que sinaliza para um ín com carga positiva altamente focada.

O potencial iônico não é um conceito novo. Os geoquímicos remontam este conceito ao trabalho de Victor Goldschmidt (1937), que produziu o clássico diagrama ainda utilizado em muitos livros 
texto. Neste diagrama linhas que se irradiam da origem são linhas de igual potencial iônico, e são mostradas duas isolinhas que dividem os íons em um campo de íons solúveis, íons que são insolúveis e formam hidróxidos, e íons solúveis em oxiânions (e.g., $\mathrm{S}^{6+}$ no íon sulfato). No entanto, Goldschmidt não foi o primeiro a considerar o potencial iônico. Esta idéia surgiu quase uma década antes do artigo de Goldschmidt, trazida por Cartledge (1928a, 1928b), que apresentou o potencial iônico como uma função periódica e discorreu sobre suas propriedades, mostrando um mesmo elemento químico aparecendo pelo menos duas vezes na tabela periódica. Nesse aspecto sua tabela é uma predecessora da tabela apresentada por Railsback (2003). Com este conceito de potencial iônico, é possível apresentar um novo formato de tabela periódica, calculando o potencial iônico para cada íon. Novamente, $\mathrm{o} \mathrm{Ca}^{2+}$ é um bom exemplo: uma carga de 2 e um raio de $1 \AA ̊$ que produz um potencial iônico de 2. Calculando-se o potencial iônico para cada íon, são delineados contornos nos resultados (linhas de mesmo potencial). Criar contornos para linhas de mesmo potencial iônico insere padrões bem definidos na tabela periódica.

\section{PADRÕES E TENDÊNCIAS NA TABELA}

Os símbolos na Tabela Periódica dos Elementos e seus Íons para Cientistas da Terra mostram ocorrências naturais ou enriquecimento em minerais, águas naturais, solos e sedimentos, rochas ígneas, o manto e a atmosfera, assim como nutrientes críticos (Fig. 1). Estes símbolos encontram-se em faixas que acompanham contornos de mesmo potencial iônico ao longo da tabela, como seria esperado a partir de Cartledge (1928a , 1928b), Goldschmidt (1937) e Mason (1958). Como resultado a nova tabela evidencia padrões geoquímicos que não aparecem na tabela convencional. Por exemplo, muitos íons com potencial iônico entre 3 e 10 formam óxidos, estão concentrados no solo e nódulos marinhos de Fe-Mn, formam fases ígneas precoces e são menos empobrecidos no manto. O resultado é uma faixa vermelha e marrom ao longo dos cátions duros e intermediários na nova tabela (Fig. 1). A mesma faixa de cátions duros inclui aqueles que compõem óxidos com maior módulo de compressibilidade (Inserção 1), maior dureza (Inserção 2), temperatura de fusão mais elevada (Inserção 3) e menor solubilidade (Inserção 4).
Por outro lado, cátions duros com potencial iônico $<4$ formam os fluoretos, incluem íons abundantes nas águas dos rios e do mar, e incluem íons importantes como nutrientes. Cátions com potencial iônico $>8$, do mesmo modo, incluem íons abundantes na água do mar, íons importantes como nutrientes, e íons que formam oxissais, tais como sulfatos e arsenatos. Os resultados encontram-se nas faixas azul e verde ao longo na nova tabela. Estas faixas estendem-se dos cátions duros (que coincidem com os elementos litófilos) aos cátions intermediários a moles (que coincidem de maneira geral com os elementos siderófilos e calcófilos).

Contornos de mesmo potencial iônico que se prolongam dos cátions duros aos cátions intermediários (p.ex., $\mathrm{Mn}^{4+} \mathrm{e} \mathrm{Fe}^{3+}$ ), permanecem na faixa vermelha e marrom ao longo da tabela, de forma que cátions intermediários com potencial iônico entre 3 e 8 também formam óxidos, estão concentrados em solos, entram em fases ígneas precoces e etc. Por outro lado, os contornos para os potenciais iônicos mais baixos (1 e 2) ressaltam os cátions moles, que incluem os metais de cunhagem $(\mathrm{Cu}, \mathrm{Ag}$ e $\mathrm{Au})$ e formam o centro de uma região caracterizada por diamantes amarelos que marcam íons formadores de sulfetos, brometos e iodetos.

Os metais de cunhagem e seus vizinhos também são mostrados em uma seção da tabela realçando suas formas no estado elementar (a verdadeira "Tabela dos elementos" dentro da nova tabela). Os símbolos e campos coloridos mostram que os grupos desses elementos formam ligas. Por exemplo, elementos que se ligam com Os constituem um grupo pequeno distinto, e elementos que compõe ligas com $\mathrm{Fe}$ constituem um grupo de pequena superposição com elementos que formam ligas com $\mathrm{Cu}$ e Au.

Padrões entre os ânions do lado direito da tabela são similares aos padrões para os cátions duros que aparecem do lado esquerdo da mesma. Entre os ânions de potencial iônico baixo, uma faixa azul-verde de símbolos pertencentes a solutos é análoga à faixa observada nos cátions de baixo potencial iônico. Da parte superior à parte inferior, encontra-se a transição dos ânions coordenando com cátions duros (resultando em fluoretos e óxidos de $\mathrm{Na}^{+}$, $\mathrm{K}^{+} \mathrm{e} \mathrm{Al}^{3+}$ ) para aqueles coordenando com cátions moles (resultando em sulfetos, brometos e teluretos de $\mathrm{Ag}^{+}$e $\left.\mathrm{Au}^{+}\right)$. Da direita para a esquerda, ou do $\mathrm{Cl}^{-}$e $\mathrm{F}^{-}$para o O $\mathrm{O}^{2-}$ ao $\mathrm{C}^{4}$, está a transição dos ânions que formam minerais com cátions duros de potencial iônico baixo (p.ex. $\mathrm{K}^{+}$e $\mathrm{Na}^{+}$) para aqueles que compõem minerais com cátions duros de potencial 
iônico mais elevado (p.ex., $\mathrm{Al}^{3+}$ e $\mathrm{Si}^{4+}$ ). Minerais exemplificando essa transição são carrobita (KF), sellaíta $\left(\mathrm{MgF}_{2}\right)$, gibbsita $\left(\mathrm{Al}_{2} \mathrm{O}_{3}\right)$ e moissanita $(\mathrm{SiC})$.

A especiação dos cátions duros em solução aquosa também segue padrões facilmente reconhecíveis na nova tabela (linhas retas pretas em negrito na Fig. 1). Da parte inferior à esquerda na parte superior à direita através dos cátions duros, a especiação evolui de hidratação (p.ex. $\mathrm{K}^{+}$) para hidroxo-complexos [p.ex., $\mathrm{Al}(\mathrm{OH})_{\mathrm{n}}{ }^{3-\mathrm{n}} \mathrm{e} \mathrm{Si}(\mathrm{OH})_{4}{ }^{0}$ ] para oxo-hidroxo-complexos (p.ex., $\mathrm{COOOH}^{-} \mathrm{e}$ $\mathrm{POOOOH}^{-}$, mais familiares como $\mathrm{HCO}_{3}^{-} \mathrm{e} \mathrm{HPO}_{4}^{-}$ ) para oxo-complexos (p.ex., $\mathrm{CO}_{3}^{2-}, \mathrm{NO}_{3}^{-} \mathrm{e} \mathrm{SO}_{4}^{2-}$ ) (Stumm \& Morgan 1996, Shock et al. 1997). Uma tendência que também é imperceptível na tabela periódica convencional torna-se assim facilmente compreensível na nova tabela. Estes padrões de coordenação, quando estendidos de solução para sólidos, colocam no contexto a existência de minerais oxissais tais como carbonatos, nitratos e sulfatos, mas não "calciatos" ou "sodiatos", e a existência de aluminato apenas como uma espécie aquosa (Pokrovskii \& Helgeson 1997).

Muitos desses padrões podem ser explicados considerando a força da ligação e blindagem da carga em estruturas minerais, como é mostrado esquematicamente na inserção 7. Os cátions de potencial iônico baixo (p.ex., $\mathrm{K}^{+}, \mathrm{Na}^{+}, \mathrm{Sr}^{2+}$ ) ligam-se apenas fracamente ao $\mathrm{O}^{2-}$, de maneira que não formam óxidos e não ficam retidos nos ambientes formadores de óxidos e hidróxidos, como solos. Ao invés disso, eles são solúveis em soluções aquosas, passando às águas naturais e cruzando membranas de células e revestimentos de raízes como nutrientes. Suas ligações fracas com $\mathrm{O}^{2-}$ resultam em sua incorporação aos minerais ígneos apenas a temperaturas relativamente baixas, formando minerais tardiamente na sequência de cristalização. Cátions de potencial iônico intermediário (p.ex., $\mathrm{Al}^{3+}, \mathrm{Ti}^{4+}$ ) formam ligações relativamente fortes com $\mathrm{O}^{2-}$, e sua coordenação tetraédrica a cúbica permite a blindagem dos cátions de cargas positivas uns dos outros. Assim, estes formam óxidos e hidróxidos estáveis em ambientes oxidantes, e muitos deles fazem ligações a altas temperaturas em minerais ígneos, entrando nos estágios iniciais da sequência de cristalização. A sua estabilidade como óxidos e hidróxidos resulta em baixa solubilidade e baixa concentração em águas naturais, conduzindo assim à sua irrelevância enquanto nutrientes. Cátions de potencial iônico alto (p.ex., $\mathrm{P}^{5+}, \mathrm{N}^{5+}, \mathrm{S}^{6+}$ ) formam ligações muito fortes com $\mathrm{O}^{2-} \mathrm{em}$ radicais como
$\mathrm{PO}_{4}^{3-}, \mathrm{NO}_{3}^{-}{ }^{-}$e $\mathrm{SO}_{4}^{2-}$, mas sua concentração intensa de carga positiva incompletamente blindada, e resultante repulsão, impedem a formação de minerais óxidos e hidróxidos. Assim, como cátions de potencial iônico baixo, estes são solúveis em solução aquosa, abundantes em águas naturais e cruzam as membranas das células e o revestimento das raízes como nutrientes. Sua concentração de carga positiva faz com que estes cátions entrem em minerais ígneos tão tardiamente, que se encontram entre os íons "incompatíveis" na cristalização de magmas silicáticos.

Estas considerações ajudam a explicar a existência, e não-existência, de oxissais (inserção 5). Silicatos simples (silicatos sem $\mathrm{OH}^{-}$e/ou $\mathrm{H}_{2} \mathrm{O}$ ) desenvolvidos à volta de $\mathrm{Si}^{4+}$ podem acomodar cátions $1+\mathrm{a} 4+$. Boratos e fosfatos simples, edificados à volta de cátions de potencial iônico maior $\left(\mathrm{B}^{3+} \mathrm{e}^{5+}\right)$, podem acomodar apenas cátions $1+\mathrm{a}$ $3+$, provavelmente porque a carga residual positiva dos grupos borato e fosfato repele os cátions $4+$. Carbonatos e sulfatos simples, organizados ao redor de cátions de potencial iônico até maior, acomodam apenas cátions $1+$ e $2+$. Finalmente, nitratos simples organizados ao redor do minúsculo $\mathrm{N}^{5+}$ altamente carregado, acomodam apenas os cátions $1+$, provavelmente porque a carga positiva não blindada dos grupos nitrato repele qualquer cátion de carga $2+$ ou maior. As mesmas tendências, com limites deslocados, existem em minerais análogos com $\mathrm{OH}^{-}$e/ou $\mathrm{H}_{2} \mathrm{O}$ (p.ex., nitratos hidratados acomodam cátions $1+$ e $2+$, mas não os de carga mais elevada, e os sulfatos portadores de $\mathrm{OH}$ e carbonatos acomodam cátions $1+$ a $3+$, mas não os $4+$ ). O resultado é um modelo que permite predizer a existência ou inexistência de minerais oxissais de vários cátions.

\section{GENERALIDADES}

Talvez a compreensão geral mais clara aparente da nova tabela é que o intemperismo químico na superfície da Terra e a evolução da Terra para separar o manto e a crosta continental são geoquimicamente processos muito similares: a segregação dos cátions duros e intermediários de alto e baixo potencial iônico daqueles de potencial iônico intermediário. O resultado é (1) concentração de muitos destes cátions de potencial iônico intermediário no manto e na superfície da Terra, no solo (as faixas vermelhas e marrons na tabela) e (2) e a remoção final de íons de baixo e alto potencial 
iônico para os oceanos (faixas azuis na tabela). O processo continua nos oceanos, quando cátions de potencial iônico intermediário são segregados em nódulos de Fe-Mn e têm um tempo de residência curto na água do mar.

Um outro processo básico na Terra - a vida seguiu regras similares àquelas que ditaram a evolução do manto e o intemperismo. Como a vida iniciou-se e evoluiu em grande parte em solução aquosa e porque as entidades químicas devem estar dissolvidas para passar através das membranas das células, a vida aproveita e depende das formas químicas solúveis. Os nutrientes críticos para a vida (símbolos verdes na tabela) são consequentemente coincidentes com as espécies químicas dissolvidas nas águas naturais (símbolos azuis na tabela). A transição evolucionária de algumas formas de vida para a terra coloca-as em um ambiente no qual o intemperismo químico remove tais íons dos solos. O resultado é um enigma para a vida das plantas afins por água: solos ricos em nutrientes são os mais comuns em regiões áridas onde estes nutrientes não foram removidos por intemperismo, e solos onde as condições úmidas favorecem a vida são tipicamente lixiviados de nutrientes. A utilização de íons \pm 1 , tanto por plantas como por animais exemplifica este desafio evolucionário: os agricultores modernos normalmente estimulam o crescimento das plantas com fertilizantes portadores de $\mathrm{K}^{+}$, vertebrados frequentemente lambem sal para $\mathrm{Na}^{+}$, e as sociedades pré-modernas comercializavam $\mathrm{NaCl}$ como substância preciosa. Os humanos modernos continuam a tendência, pois consumem $\mathrm{NaCl}$ suplementado com $\mathrm{I}^{-}$, água suplementada com $\mathrm{F}^{-}$, consomem bebidas esportivas com $\mathrm{K}^{+}$e mesmo tomam pílulas com $\mathrm{Li}^{+}$.

\section{SEIS EXEMPLOS AO LONGO DA TABELA PERIÓDICA}

\section{A natureza especial do silício}

Adicionalmente às tendências já delineadas, muitos casos especiais importantes tornam-se claros com a nova tabela. Por exemplo, o $\mathrm{Si}^{4+}$ é único por ser muito abundante (é o segundo constituinte mais abundante da crosta) e por ter um potencial iônico no limite entre os cátions relativamente insolúveis de potencial iônico intermediário (p.ex., $\mathrm{Al}^{3+}, \mathrm{Ti}^{4+}$ e $\mathrm{Sc}^{3+}$ na faixa vermelha e marrom $\mathrm{da}$ tabela) e os cátions de potencial iônico alto que formam radicais solúveis (p.ex., $\mathrm{C}^{4+}, \mathrm{N}^{5+}, \mathrm{P}^{5+} \mathrm{e}$ $\mathrm{S}^{6+}$ na faixa azul e verde). $\mathrm{O} \mathrm{Si}^{4+}$ é assim abundante tanto em resíduos do intemperismo (p.ex., em areias ou solos arenosos ou cauliníticos), quanto em águas naturais, tais como água dos rios (onde a sílica dissolvida é a segunda espécie mais abundante dissolvida) e água do mar (onde é a 11 a espécie dissolvida mais abundante).

A abundância e o potencial iônico fronteiriço do $\mathrm{Si}^{4+}$ também têm implicações importantes na petrologia ígnea. A maior parte dos minerais ígneos são silicatos, mas algumas das primeiras fases a se formarem em rochas ígneas (p.ex., espinélio e cromita) não contêm absolutamente $\mathrm{Si}$, e os primeiros minerais portadores de $\mathrm{Si}$ a se formar são forsterita (onde o $\mathrm{Mg}$ é mais abundante do que o $\mathrm{Si}$ ) e anortita (onde $\mathrm{Ca}$ e $\mathrm{Al}$ excedem o Si em número) (inserção 3). Apenas nas fases tardiamente formadas o $\mathrm{Si}^{4+}$ torna-se o cátion dominante, e apenas no final da série de reação de Bowen (quando os elementos incompatíveis entram nos sólidos) o $\mathrm{SiO}_{2}$ forma-se como quartzo (inserção 3). Este paradoxo do $\mathrm{Si}^{4+}$ como um íon de certa forma incompatível na cristalização de magmas silicáticos, surge porque o $\mathrm{Si}^{4+}$ encontra-se no limite superior dos potenciais iônicos que permitem a formação de óxidos estáveis. De fato, $\mathrm{Si}^{4+}$ está apenas a um passo do $\mathrm{C}^{4+}$, $\mathrm{N}^{5+} \mathrm{e}^{5+}$, que não formam absolutamente nenhum óxido por causa de seu alto potencial iônico, além de serem "incompatíveis" na petrologia ígnea.

A abundância e o potencial iônico limítrofe do $\mathrm{Si}^{4+}$ também levam a uma feição interessante da fisiologia das plantas. As plantas absorvem nutrientes $\mathrm{NO}_{3}^{-}$como solutos, e o potencial iônico limite do $\mathrm{Si}^{4+}$ deixa-o ser absorvido como um soluto [como $\mathrm{H}_{4} \mathrm{SiO}_{4}{ }^{0}$, ou mais exatamente como $\mathrm{Si}(\mathrm{OH}){ }_{4}^{0}$ ]. No entanto, o $\mathrm{Si}^{4+}$ é insolúvel de tal forma que algumas plantas armazenam massas de sílica opalina em seus tecidos (Meunier \& Colin 2001). Estas acumulações minerais nas plantas, chamadas fitólitos, existem porque o $\mathrm{Si}^{4+}$ é suficientemente abundante e solúvel para ser absorvido através das raízes em solução, mas suficientemente insolúvel para ser mantido como mineral sólido no interior de um tecido de planta úmido.

\section{A natureza extraordinária do ouro}

Se o Si tem um papel especial na geoquímica por causa de sua abundância e de sua localização limite em potencial iônico, o Au é especial pelas 
razões opostas: é extremamente raro, tem um potencial iônico extremamente baixo como $\mathrm{Au}^{+}$, e $\mathrm{Au}^{+}$é extremamente "mole" no espectro dos cátions duros a moles. Como resultado, Au não forma óxidos e nem mesmo forma sulfeto apenas de $\mathrm{Au}$; os únicos análogos de um hipotético $\mathrm{AuS}_{2}$ são dois minerais de $\mathrm{AuTe}_{2}$ e um mineral $\mathrm{AuBi}_{2}$. A predileção do Au por ânions grandes também é vista em sua extensiva complexação com $\mathrm{Cl}^{-} \mathrm{em}$ solução, à qual é atribuído muito do transporte do ouro para gerar depósitos minerais (p.ex., Murphy et al. 2000). Por outro lado, a indiferença do Au para com o oxigênio é mais uma das razões pela qual o Au tem sido tão valorizado pelos humanos - ele continua a brilhar como um metal não oxidado apesar de séculos de exposição ao $\mathrm{O}_{2}$. Na tabela periódica convencional, o Au é simplesmente um dos muitos elementos no meio daquela tabela, mas seu isolamento por contornos de mesmo potencial iônico ilustra sua natureza única na nova tabela periódica.

\section{Aplicações de Fe, Mn e Ce como indicadores paleoredox}

A separação dos cátions da tabela e a consideração do potencial iônico mostram porque alguns cátions têm sido extensivamente utilizados na avaliação de condições paleoredox. Por exemplo, Fe e Mn têm sido utilizados em estudos geoquímicos de oxidação e redução (p.ex., Hem 1972), porque eles são decididamente os elementos mais abundantes que formam os cátions não duros. Eles são assim os elementos mais abundantes que podem sofrer mudanças de uma unidade no estado de oxidação (p.ex., entre $2+$ e $3+$ para $\mathrm{Fe}$ ). Em condições oxidantes eles são íons pequenos altamente carregados $(=3+)$ que são insolúveis por causa de seu alto potencial iônico e resultante formação de hidróxidos. Em condições redutoras, eles são íons menos carregados $(2+)$ e maiores, que desta forma têm potencial iônico menor e são solúveis. $\mathrm{O} F$, consequentemente, se comporta como o íon $\mathrm{Al}^{3+}$ formador de solos e óxidos, quando oxidado a $\mathrm{Fe}^{3+}$, mas se comporta como o "intemperizável" e solúvel ín $\mathrm{Mg}^{2+}$, quando reduzido a $\mathrm{Fe}^{2+}$.

O Ce é menos abundante que o Fe e Mn, mas por outro lado é análogo porque precipita em sólidos quando oxidado a $\mathrm{Ce}^{4+}$, mas é mais solúvel como $\mathrm{Ce}^{3+}$. Isto fornece um indicador de oxigenação em oceanos modernos (de Baar et al. 1988) e antigos (Wright et al. 1987). $\mathrm{Ce}^{3+} \mathrm{e} \mathrm{Ce}^{4+}$ também exemplificam padrões de coordenação vistos em outras partes da tabela, quando o íon com um potencial iônico mais baixo forma um fluoreto, fluorecita com Ce, enquanto o íon com potencial iônico maior forma um óxido, a cerianita. A formação destes dois minerais compara-se à formação de fluoretos por $\mathrm{Na}^{+}$e $\mathrm{K}^{+}$, mas formação de óxidos por $\mathrm{Al}^{3+}$ e Sc$^{3+}$ (Fig. 1).

\section{Urânio, tório e problemas de datação}

A datação radiométrica usando o método da série do U (Edwards et al. 1987) constitui um meio valioso de determinar a idade de materiais mais novos do que $\sim 500$ k.y. Um problema com o método, no entanto, é que o U na superfície da Terra está no estado $\mathrm{U}^{6+}$ e assim na forma do oxo-complexo solúvel $\mathrm{UO}_{2}{ }^{2+}$ (Langmuir 1978). O Th, por outro lado, ocorre como $\mathrm{Th}^{4+}$, que é insolúvel (p.ex. Kaufman 1969). Como resultado, o U pai é comumente perdido dos materiais, mas o Th filho permanece, fornecendo idades antigas incorretas (p.ex. Dabous \& Osmond 2000). Este problema não é perceptível a partir da tabela periódica convencional, mas é previsível na nova tabela, onde o $\mathrm{U}^{6+}$ localiza-se na faixa azul e verde dos cátions duros relativamente solúveis de alto potencial iônico e o $\mathrm{Th}^{4+}$ encontra-se na faixa vermelha e marrom dos íons relativamente insolúveis de potencial iônico intermediário.

\section{De silicatos a selenitos}

Como já discutido, o $\mathrm{Si}^{4+}$ está localizado no limite entre cátions de potencial iônico intermediário a alto na nova tabela. Um resultado é que o $\mathrm{Si}^{4+}$ é um dos poucos cátions que forma ambos, óxidos (quartzo) e oxissais (os muitos silicatos). $\mathrm{V}^{3+}$ e $\mathrm{Mo}^{6+}$ são cátions duros com aproximadamente o mesmo potencial iônico, e eles também formam óxidos (shcherbinaíta e molibdita) e oxissais (os vanadatos e molibdatos). Se for seguido o contorno para $z / r=8$ destes cátions duros para os cátions moles e intermediários (Fig. 1), chega-se ao $\mathrm{Se}^{4+}$, que analogamente forma um óxido (downeyita) e oxissais (os selenitos). Como $\mathrm{Si}^{4+}, \mathrm{V}^{5+} \mathrm{e} \mathrm{Mo}^{6+}$, o $\mathrm{Se}^{4+}$ é também um cátion essencial à nutrição dos vertebrados (McDowell 1992, Sunde 1997). Estas similaridades ilustram a continuidade das tendências ao longo dos contornos de igual potencial ao longo da tabela. A principal diferença no comportamento do Se é que este forma cátions com vários 
elétrons nas camadas externas e assim existe tanto como $\mathrm{Se}^{6+}$ bem como $\mathrm{Se}^{4+}$. O Se $\mathrm{Se}^{6+}$ também forma minerais oxissais (os selenatos) e é importante na nutrição, mas exatamente como seria esperado, seguindo-se o contorno de mesmo potencial para $z / r=16$ do $\mathrm{P}^{5+}$ e $\mathrm{S}^{6+}$ nos cátions duros (Fig. 1), o $\mathrm{Se}^{6+}$ não forma óxidos. Uma abordagem mais detalhada acerca dos padrões na composição de oxissais e sulfossais, bem como sobre a natureza paradoxal do quartzo, pode ser encontrada em Railsback (2007).

\section{0 papel singular do cloreto - "Faz de tudo um pouco, mas nada direito"}

$\mathrm{O} \mathrm{Cl}^{-}$não é abundante como o $\mathrm{F}^{-}$na crosta, mas $\mathrm{Cl}^{-}$é mais abundante que o $\mathrm{F}^{-}$na maior parte das águas naturais. A razão para este paradoxo pode ser vista na nova tabela. $\mathrm{O} \mathrm{Cl}^{-}$ocupa uma posição intermediária entre os ânions à direita da tabela, de forma que coordena com cátions duros para formar minerais solúveis como silvita e halita e coordena com cátions moles para formar minerais relativamente raros como clorargirita $(\mathrm{AgCl})$ (Fig. 1). Por comparação, $\mathrm{F}^{-}$se liga com os cátions duros com força suficiente para formar minerais insolúveis como fluorita e assim é sequestrado por estes, deixando relativamente baixas concentrações nas águas naturais. $\mathrm{O} \mathrm{Cl}^{-}$, em contraste, não se liga fortemente nem com os cátions duros, nem com os moles, formando assim apenas minerais relativamente solúveis (inserção 8). Desta forma, pode atingir altas concentrações em águas naturais e comumente só precipita quando ele $\left(\mathrm{Cl}^{-}\right)$e um cátion fracamente ligado, $\mathrm{Na}^{+}$, finalmente adquirem saturação com respeito à halita.

\section{CONCLUSÃO}

A organização na Tabela Periódica dos Elementos e seus Íons para Cientistas da Terra, de acordo com a carga, produz um arranjo mais útil para reconhecer as tendências geoquímicas que o da tabela periódica convencional. Estas tendências em mineralogia, geoquímica das soluções aquosas, petrologia ígnea, geoquímica do manto, química do solo e sedimentos, e química dos nutrientes são largamente controladas pela coordenação de cátions com $\mathrm{O}^{2-}$. Esta síntese da geoquímica do manto ao solo à água do mar fornece a estrutura para entender os sistemas da Terra e predizer relações geoquímicas que não são reconhecíveis com as tabelas periódicas organizadas convencionalmente com base nos elementos.

\section{AGRADECIMENTOS}

A preparação da Figura 1 - Tabela Periódica foi realizada durante os anos de 2009 e 2010, com a valiosa colaboração de Dayvison Bruno Cordeiro de Paiva (Estudante de Graduação do Curso de Geologia - Centro de Ciências Exatas e da Terra - UFRN) e Ítalo Guimarães Medeiros da Silva (Estudante de Graduação do Curso de Química Centro de Ciências Exatas e da Terra - UFRN), a quem expressamos nossos agradecimentos.

\section{REFERÊNCIAS}

Bernal J.P., Railsback L.B. 2008. Introducción a la Tabla Periódica de los Elementos y sus Iones para Ciencias de la Tierra. Revista Mexicana de Ciencias Geológicas, 25(2):236-246.

Cartledge G.H. 1928a. Studies on the periodic system. I. The ionic potential as a periodic function. Journal of the American Chemical Society, 50(11): 2855-2863.

Cartledge G.H. 1928b. Studies on the periodic system. II. The ionic potential and related properties. Journal of the American Chemical Society, 50(11): 2863-2872.

Courtney A.1999. A brief history of the development of the periodic table. http://www.wou.edu/las/physci/ ch412/perhist.htm.

Dabous A.A., Osmond J.K. 2000. U/Th study of speleothems from the Wadi Sannur Cavern, Eastern Desert of Egypt. Carbonates and Evaporites, 15: 1-6.

De Baar H.J.W., German C.R., Elderfield H., van Gaans P. 1988 Rare earth element distributions in anoxic waters of the Cariaco Trench. Geochimica et Cosmochimica Acta, 52: 1203-1219.

Edwards R.L., Chen J.H., Wasserburg G.J. 1987. ${ }^{238} \mathrm{U}_{-}{ }^{234} \mathrm{U}_{-}{ }^{230} \mathrm{Th}-{ }^{232} \mathrm{Th}$ systematics and the precise measurement of time over the past 500,000 years. Earth and Planetary Science Letters, 81: 175-192.

Farber E. 1969. The Evolution of chemistry. New York: Ronald Press. 437p.

Gaines R.W., Skinner H.C.W., Foord E.E., Mason R., Rosenzweig A. 1997. Dana's new mineralogy (eight edition). New York: John Wiley and Sons. 1819 p.

Goldschmidt V.M. 1937. The principles of distribution of chemical elements in minerals and rocks. Journal of the Chemical Society, 655-673. The seventh Hugo Müller Lecture delivered before the Chemical Society on March 17th, 1937.

Hem J.D. 1972. Chemical factors that influence the availability of iron and manganese in aqueous 
solutions. Geological Society of America Bulletin, 83: 443-450.

Jin C.Y. 2006. Understanding an earth scientist's periodic table of the elements and their ions. Journal of Jinhua College of Profession and Technology, 6(1):71-75.

Kaufman A. 1969. The Th-232 concentration of surface ocean water. Geochimica et Cosmochimica Acta, 33:717-724.

Langmuir D. 1978. Uranium solution-mineral equilibria at low temperatures with applications to sedimentary ore deposits. Geochimica et Cosmochimica Acta, 42:547-570.

Mason B. 1958. Principles of Geochemistry. New York: John Wiley and Sons. 310 p.

McDonough W.F., Sun, S.-s. 1995. The composition of the Earth. Chemical Geology, 120:233-253.

McDowell L.R. 1992. Minerals in animal and human nutrition. San Diego: Academic Press. 524 p.

Meunier J.D., Colin F., eds. 2001. Phytoliths: Applications in earth sciences and human history. Exton, Pennsylvania: A.A. Balkema Publishers. 378 p.

Murphy P.J., Stevens G., LaGrange M.S. 2000. The effects of temperature and pressure on gold-chloride speciation in hydrothermal fluids: A Raman spectroscopic study. Geochimica et Cosmochimica Acta, 64:479-494.

Pokrovskii V.A., Helgeson H.C. 1997. Thermodynamic properties of aqueous species and the solubilities of minerals at high pressures and temperatures; the system $\mathrm{Al}_{2} \mathrm{O}_{3}-\mathrm{H}_{2} \mathrm{O}-\mathrm{KOH}$. Chemical Geology, 137:221-242.
Railsback L.B. 2003. An earth scientist's periodic table of the elements and their ions. Geology, 31(9):737-740.

Railsback L.B. 2007. Patterns in the composition of oxysalt and sulfosalt minerals, and the paradoxical nature of quartz. American Mineralogist, 92:356-369.

Railsback L.B. 2012. An earth scientist's periodic table of the elements and their ions. Version 4.8e. URL: http://www.gly.uga.edu/railsback/ PT/815Periodic Table48e02.pdf.

Ringwood A.E. 1955. The principles covering trace element distribution during magmatic crystallization: Part I. The influence of electronegativity. Geochimica et Cosmochimica Acta, 7:189-202.

Shock E.L., Sassani D.C., Willis M., Sverjensky D.A. 1997. Inorganic species in geologic fluids; correlations among standard molal thermodynamic properties of aqueous ions and hydroxide complexes. Geochimica et Cosmochimica Acta, 61:907-950.

Stumm W., Morgan J.J. 1996. Aquatic chemistry (third edition). New York: John Wiley and Sons, 1022 p.

Sunde R.A. 1997. Selenium, in O'Dell B.L., eds., and Sunde R.A., eds., Handbook of nutritionally essential mineral elements. New York: Marcel Dekker, Inc., p. 493-556.

Wright J., Schrader H., Holser W.T. 1987. Paleoredox variations in ancient oceans recorded by rare earth elements in fossil apatite. Geochimica et Cosmochimica Acta, 51:631-644. 